\title{
National Hospital Accreditation as an External Assessment Tool
}

\author{
Keziban Avcı
}

Department of Health Management, Ankara Yildirim Beyazit University, Ankara, Turkey

\begin{abstract}
The focus on quality measurement in healthcare for improvements is crucial. Thus, a valid model for quality assessment is needed to achieve governance and quality improvement. The growing and changing global and national health priorities both the improvement and measurement mechanisms play an important role in the positive impact on health systems. This paper aims to evaluate the Turkish Health Care Quality and Accreditation Institute (TUSKA), which a national institute and carry out accreditation activities in health services, used to the accreditation survey program as an external evaluation tool. Keywords: Accreditation; assessment; hospital; process assessment; reliability.
\end{abstract}

$T$ o provide more qualified and efficient health services, the health system has gained new ground since 2003 after various reforms have been applied and a series of transformations have been implemented in healthcare setups to meet the increasing patient expectations in Turkey ${ }^{[1]}$. One of the regulations made in this context is the regulation implemented to accredit health institutions. Assessment of the health services can only be made by evaluating the criteria, indicators and standards determined with the purpose of hospital accreditation programs, through independent evaluators ${ }^{[2]}$.

Accreditation standards are based on evidence-based instructions, conceptual, organizational models, and expert consensus. Compliance with accreditation standards is seen as an indicator/adequacy of how well health services are organized ${ }^{[3]}$. In other words, compliance with standards is the establishment of a culture of safety and quality in an institution, along with continuous improvement in patient care processes. It is in this light that a way to establish a quality management system in health services will be inaugurated $^{[2]}$.
Accreditation of health institutions requires consistency and coordination of the assessments made by independent surveyors $^{[4]}$. The most critical issue in surveys is reliability among surveyors ${ }^{[5]}$. In this context, it is an important skill to know how and how reliable assessment will be made for surveyors ${ }^{[6]}$. However, individual judgments are a concern regarding consistency in accreditation survey and ensuring reliability and consistency among surveyors is essential to establish trust in accreditation programs ${ }^{[7]}$.

The necessity of a reliable evaluation in health services is important about providing and maintaining trust to health professionals, specialists and institutions. Along with the reliability and the availability and thus the interpretation of valid evidence and because of a need for professional opinion, the process of evaluating patient outcomes, service provider behaviors, and health care quality is affected by changes in organizational structure and processes ${ }^{[8]}$. In this context, concerning ensuring reliability in accreditation programs, it is important that the surveys are carried out through independent ${ }^{[4]}$ and expert evaluators who have been subjected to a training

Correspondence (iletişim): Keziban Avcı, PhD. Ankara Yildirim Beyazıt Universitesi, Sağlık Yönetimi Bölümü, Ankara, Turkey Phone (Telefon): +90 5462251193 E-mail (E-posta): kezibanavci1@gmail.com 
program $[4,9-11]$, both providing and benefiting from the service $^{[9]}$. Also, the use of a defined Survey Method or program ${ }^{[4-10]}$ not only during the training but also during the data collection phase ${ }^{[4,9,12]}$ of the evaluators seems to depend on the existence of discussion and consensus ${ }^{[4,12]}$ among independent surveyors and assessment workforce ${ }^{[4]}$ management.

In this study, the aim is to evaluate the accreditation survey program of the national institute, the Turkish Health Care Quality and Accreditation Institute (TUSKA), which carries out accreditation activities in health services as an external evaluation tool.

\section{TUSKA and Accreditation Program}

The phrase "Quality and Accreditation for Qualified and Effective Health Services" has been included as a constituent of the Health Transformation Program, which was promulgated in $2003^{[1]}$. In this context, based on the necessity of a system that will evaluate the compliance with the standards in the health service delivery process in the Official Gazette dated 26 November 2014 and numbered 29187, the establishment of Turkey Institutes of Health Directorate with the 6569 numbered law, the Amendment of Certain Laws and Decrees was published. As it is stated in the law, among the duties of the Turkish Institutes of Health Sciences (TUSEB), which aims to serve humanity by producing information in the fields of health service provision, the science of health and technologies, is to carry out accreditation activities in health services. For this purpose, TUSKA was established within TUSEB and it is tasked with "contributing to the Ministry in determining the quality and accreditation rules in health services and accrediting health institutions at national and international levels"[13].

The accreditation standards and the assessor training program used in the TUSKA accreditation program are accredited by the International Society for Quality in Healthcare (ISQua $^{[14,15]}$. This is proof that the TUSKA accreditation program has internationally accepted principles and values. It is also an indication that the processes and training modules, ${ }^{[9]}$ common to the accreditation programs of wellestablished accreditation organizations are included in the TUSKA accreditation program.

\section{TUSKA Survey Method}

Among the factors affecting the reliability of accreditation programs, support structures provided to the surveyors by the employees of the accreditation agency that manage the assessment process and the structure of the rela- tions with the institutions evaluated are included ${ }^{[4,16]}$. In this context, TUSKA uses third party people (people who are not affiliated with the accreditation assessment institution and other surveyors) in accreditation assessments. Assessors referred to as third parties must be equidistant to both organizations. Thus, independent and impartial surveyors will be able to examine the subject of the assessment comprehensively and as a whole with different parties concerning all dimensions and those involved ${ }^{[17]}$. To this end, assessors involved in TUSKA accreditation are selected according to their areas of specialization to possess the knowledge and the ability to collect, analyze, and make possible and provide statistical inferences about the reliability of different assessment evidence with an interrogative approach during the assessment and are subject to theoretical and practical serial training whose level of competence is determined by examination. Assessors are continuously evaluated by other surveyors, the assessed institution and TUSKA, during the assessments. Thus, the attempt is to ensure that the decisions made by the assessment teams are reliable and consistent ${ }^{[4,9-12]}$. In other words, it is aimed to standardize the assessor's decisions. The general framework of the TUSKA Survey Method is shown in Figure $1^{[19]}$.

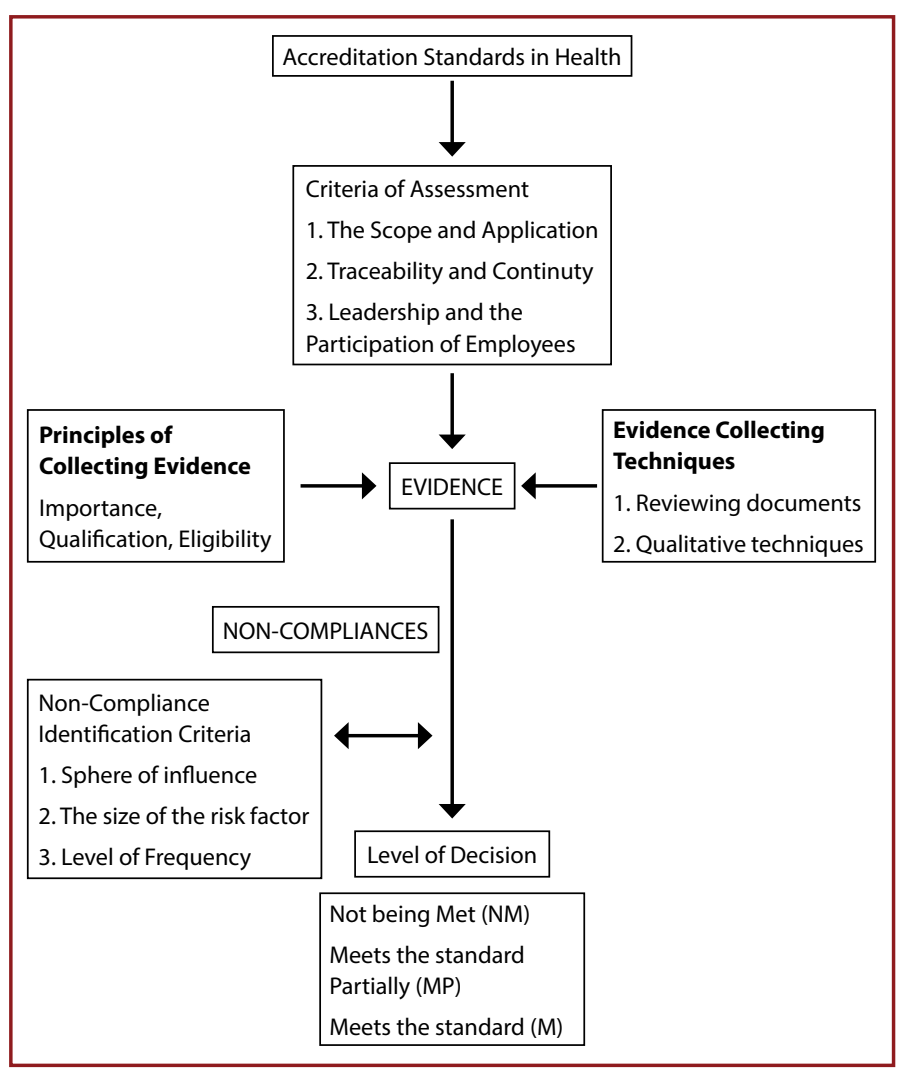

Figure 1. Framework of Survey Method of TUSKA ${ }^{[19]}$. 


\section{The Criteria of the Assessment}

The existence of three basic requirements is mandatory for accreditation. The first requirement is to establish a standard framework and identify the evidence required to demonstrate that each standard has been met, the second requirement is to construct and implement an evaluation process (accreditation assessment), and the third requirement is to monitor the compliance of the services with the standards constantly ${ }^{[9]}$. In this context, TUSKA accreditation standards cover all service areas and processes of the assessed institution concerning its dimensions and departments. From a holistic perspective, compliance with the standards is sought in all service areas and processes in which the service is provided.

Independent assessors involved in accreditation assessments act not only to conduct assessments in healthcare institutions but also as facilitators of quality improvement concepts and models ${ }^{[18]}$. This is because the activities of quality improvement are the basis of accreditation ${ }^{[20]}$. In this context, TUSKA accreditation assessment is carried out within the framework of three criteria organized to create an assessment notion that seeks and promotes the culture of quality and ensures holistic care as follows:

1. The Scope and the Application: Defining the standard according to plans, policies and processes, the fulfillment of the works and procedures for the realization of the standard in the entire institution,

2. Traceability and Continuity: To be able to track the work and its progress in the processes related to the standard and the information that manifests during the process retrospectively and simultaneously and the implementation of the said applications not only in certain periods but steadily and continuously,

3. Leadership and Participation: Involvement of managers and employees at all levels in the organization with efforts to maintain the standard, management leading the improvements and supervising the process ${ }^{[19]}$.

\section{Principles of Collecting Evidence}

In the case of health institutions assessment being linked to financing, research, or quality activities, assessment results can affect these factors significantly and directly ${ }^{[4]}$. In this context, evidence in accreditation assessment is all the information and documents used by the assessors to form their opinions. Harrington ve Pigman (2010) used the concepts of relevance, applicability, improvement, evidencebased opinion, reliability and validity when defining the desired features of quality measurement. In this context, in
TUSKA accreditation assessments, surveyors are expected to gather evidence by considering the following principles.

\section{Importance}

All the structures, processes and results that are relevant to patients, service providers, clinicians and decision-makers and which are valuable to stakeholders are important ${ }^{[21]}$. The assessor is responsible for collecting more evidence of high priority matters, which is critical for the accuracy of the judgment and the conclusions to be reached.

\section{Qualification}

It is the provision of the appropriate evidence, both qualitatively and quantitatively, for the decision to be made on the level of standard qualification. Since the surveyor cannot collect all the evidence related to the standard concerning cost and time ${ }^{[21]}$, they should be able to work on the evidence collected with the right technique, minimizing potential risks.

\section{Eligibility}

Eligibility refers to the reliability and level of relevance of the evidence that is collected.

\section{Reliability}

Reliability is the random degree of purification of the assessment. The evidence collected and the evidence gathering technique used in the assessment process should be sufficiently stable enough to justify the use of the information that is collected to arrive at a conclusion. In other words, when the same measurement processes are used for the same data, it should yield the same results if/when repeated in time ${ }^{[21]}$. It is considered that the evidence obtained directly is more reliable compared to the evidence obtained by inferences or to the evidence obtained by photocopy or fax.

\section{Relevance}

It is the feature of the evidence collected that affects the opinion about the standard. In other words, the evidence collected should be of a nature that can demonstrate the suitability and/or irrelevance of institutional processes and practices related to the standard.

The decision on what constitutes important, sufficient and relevant assessment evidence is determined by the surveyor, considering the structure of the institution under consideration, the evidence collection method applied, and the nature of the evidence obtained. 


\section{Techniques of Evidence Collection}

Braithwaite et al. (2010) argue that all components of a hospital system are interconnected, and there is an interaction between the different components. They, therefore, state that accreditation programs need a multi-method assessment that combines quantitative and qualitative data to explore the relationship between different components ${ }^{[17]}$. TUSKA expects its surveyor to examine the medical records and documents, use qualitative techniques, such as observation and interview, and to trace system and patient, provided by the institution or obtained during the inspection to discover the relationships between the components. One or both of these methods can be used to make an accurate and complete decision of the assessment opinion or the level of meeting the standards.

\section{The Decision of the Level of Meeting the Standards}

The assessor makes a decision on the standard by evaluating the implementation level, traceability and continuity of the standard, the leadership of the managers to ensure this and the level of participation of the employees.

In the occurrence of deficiency or nonconformity related to the standard, the frequency level, area of the impacts and risk dimension of the nonconformity expressed as "Nonconformity Identification Criteria" are considered. The frequency level is randomly selected to form the opinion of the surveyor, and it is considered as "low" if it is $5 \%$ and below, and "medium" if it is 6-15\% and "high" if it is 6-15\%.

The determined impact of non-conformance translates to affecting a restricted area or the overall organization or the effects of non-conformance at the individual or systemic level. If non-compliance is defined as "Individual", then, it is in a very limited area, or there are very few employees. Individual nonconformities may often occur due to employee carelessness, negligence, failure to meet professional requirements, or due to another external factor. In other words, it generally covers issues that are not included in the system designed and implemented by the institution, and also from employees or other external factors that the institution cannot be held responsible for. The impact of non-compliance at the institutional or systemic level is defined as "Systemic". This type of nonconformity includes the issues related to the planning, organization, execution, and control of the system designed by the institution.

The risk dimension is used to determine the relationship between non-compliance and patient and employee safety. The highest potential of directly related noncon- formities related to patient and employee safety is considered. Accordingly, the risk level is "low" for patients who are likely to cause little or most outpatient damage concerning patient and employee safety. It is "medium" for negativities that have the potential to cause chronic negativities, which are partially negative or fatal or not serious in terms of patient and employee safety. The risk level is defined as "high" in case of a negative or chronic, squeal, serious and/or fatal risk of negativity concerning patient and employee safety. In this context, the decision to meet the standards/evaluation criteria can take three forms as follows.

a) Meets the standard (M): If there is no nonconformity, in some cases, even if there is some, it can be decided to meet the result of the evaluation made within the scope of "Nonconformity Identification Criteria".

b) Meets the standard Partially (MP): The evaluation of the detected nonconformity within the scope of "Nonconformity Identification Criteria" can be decided to be partially met.

c) Does Not Meet the standard (NM): As a result of the evaluation of the detected nonconformity within the scope of the "Nonconformity Identification Criteria", the standard cannot be met ${ }^{[19]}$.

The decision to meet the standard is shown in Table 1. The key question that needs to be answered at this stage is whether the sample selected indicates the presence or absence of measures that represent true patient care quality ${ }^{[21]}$.

\section{Conclusion}

Accreditation for a health institution requires the existence and operability of the quality management system of the institution. It is also a strong proof that professional standards have been complied with ${ }^{[22,23]}$. For the institutions, adherence to standards increases quality. ${ }^{[3]}$ In accreditation, a third party verifies that the services provided in accordance with the standards are verified through the assessments ${ }^{[7,23]}$. At the same time, compliance with standards is a strong quality of assurance and accreditation is the tool of this assurance ${ }^{[24]}$. In this context, during the TUSKA accreditation process, using TUSKA as the institution that manages the process and independent surveyors that are not related to the assessed institution, TUSKA made the assessment process transparent and reliable by ensuring that the assessment was carried out within a methodology.

TUSKA accreditation Survey Method is considered very significant, even in theory, due to its features that ensure reaching the most accurate assessment decision, promote the culture of quality, ensure unity among the assessors and ensure the compliance of the assessment team. Expe- 
Table 1. The matrix of the level of meeting the standards [19]

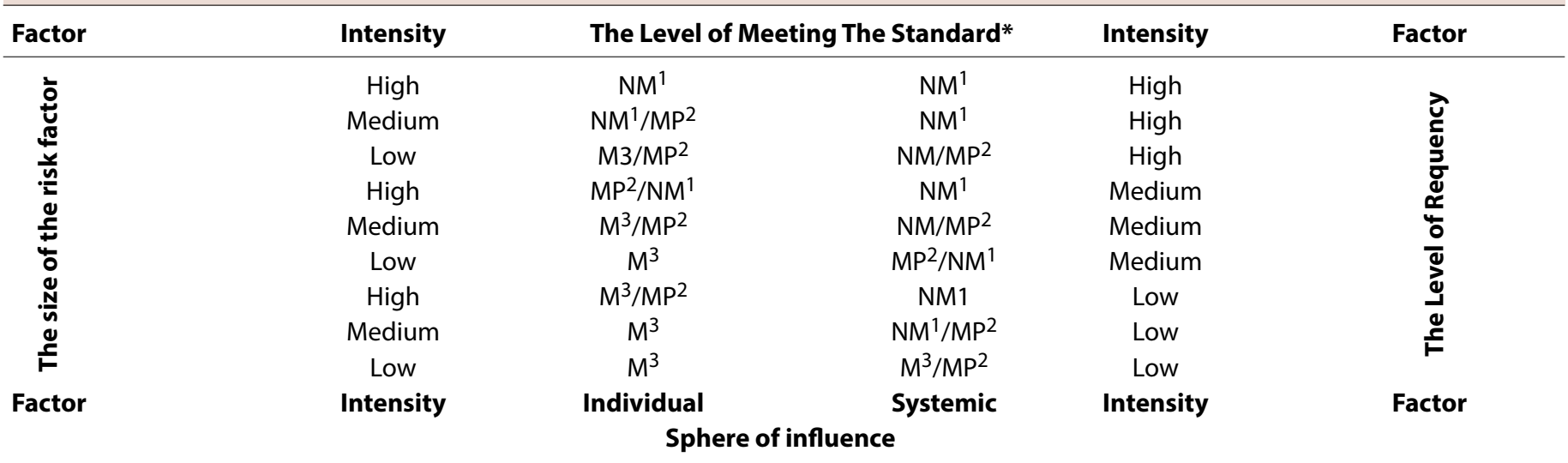

${ }^{1}$ : not being met; $^{2}$ : meets the standard partially; ${ }^{3}$ :meets the standard.

riences from prior evaluations and assessment activities also have played an important role in the design of the method in this way, and the methods have been tested as pilot applications by practitioners, managers and surveyors. However, many issues in the method can only be interpreted correctly by surveyors who have deep knowledge about the subject and can think analytically. The method will have aspects that are open to further development as it is applied in the field although the Survey Method is an important tool for accreditation assessments, the opinion of the surveyors is the determining factor. In this context, the subject matter of the qualifications of accreditation inspectors who will know, adopt and apply this method is extremely important. Given that TUSKA's surveyor training program is also accredited from ISQua provides an important advantage in this context for the selection and the assignment of surveyors.

Peer-review: Externally peer-reviewed.

Financial Disclosure: The authors declared that this study received no financial support.

\section{References}

1. Atun R, Aydın S, Chakraborty S, Sümer S, Aran M, Gürol I, et al. Universal Health Coverage in Turkey: Enhancement of Equity. Lancet 2013;382:65-99. [CrossRef]

2. Caldana G, Gabriel CS. Evaluation of the Hospital Accreditation Program: Face and Content Validation. Rev Bras Enferm 2017;70:47-53. [CrossRef]

3. Kilsdonk M, Siesling S, Otter R, Harten Wv. Evaluating the Impact of Accreditation and External Peer Review. Int J Health Care Qual Assur 2015;28:757-77. [CrossRef]

4. Greenfield D, Pawsey M, Naylor J, Braithwaite J. Researching the Reliability of Accreditation Survey Teams: Lessons Learnt
When Things Went Awry. Health Inf Manag 2013;42:4-10.

5. Greenfield D, Pawsey M, Braithwaite J. A Peer-To-Peer Model to Improve Patient Safety: Harnessing Accreditation Programs. Am J Med Qual 2012;27:353-4. [CrossRef]

6. Price E, Robinson K. The Coding Masterpiece: A Framework for the Formal Processes And Pathways of Health Classification. Health Inf Manag 2011;40:14-20. [CrossRef]

7. Greenfield D, Hogden A, Hinchcliff R, Mumford V, Pawsey M, Debono D, et al. The Impact of National Accreditation Reform On Survey Reliability: A 2-Year İnvestigation Of Survey Coordinators' Perspectives. Journal of Evaluation in Clinical Practice 2016; 22: 662-7. [CrossRef]

8. Flodgren G, Pomey MP, Taber SA, Eccles MP. Effectiveness of External Inspection of Compliance with Standards in Improving Healthcare Organisation Behaviour, Healthcare Professional Behaviour or Patient Outcomes. Cochrane Database Syst Rev 2011;(11):CD008992. [CrossRef]

9. Valori R, Rogers C, Johnston D, Ingham J. Developing a Strategy for Accreditation of Clinical Services. Clin Med (Lond) 2013;13:538-42. [CrossRef]

10. Frisino J. COA's accreditation system: checks, balances, and firewalls. BehavHealth Accred Account Alert 2002;7:1-4.

11. Teymourzadeh $E$, Ramezani $M$, Arab M, Foroushani AR, Sari AA. Surveyor Management of Hospital Accreditation Program: A Thematic Analysis Conducted in Iran. Iran Red Crescent Med J 2016;18:e30309. [CrossRef]

12. Dos Santos RA, Snell L, Tenorio Nunes MD. The Link Between Quality and Accreditation of Residency Programs: The Surveyors' Perceptions. Med Educ Online 2017;22:1270093. [CrossRef]

13. Türkiye Sağlık Enstitüleri Başkanlığı Kurulması ile Bazı Kanun ve Kanun Hükmünde Kararnamelerde Değişiklik Yapılmasına Dair Kanun. Tarih: 26 Kasım 2014, Sayı: 29187, Resmi Gazete, Ankara. Available at: https://www.mevzuat. gov.tr/Metin 1.Aspx?MevzuatKod=1.5.6569\&Mevzuatlliski=0\&sourceXmISearch=T\%C3\%BCrkiye $\% 20 \mathrm{Sa} \% \mathrm{C} 4 \%$ 9FI\%C4\%B1k\%20Enstit\%C3\%BCleri\%20Ba\%C5\%9FkanI\%C4\%B1\%C4\%9F\%C4\%B1\&Tur=1\&Tertip=5\&No=6569. 
Accessed Feb 7, 2020.

14. General Directorate of Health Services Department of Quality and Accreditation in Health. Standards of Accreditation in Health - Assessor Training Programme Guide - v1.0/2015. Ankara: Pozitif Printing Press Ltd. Co; 2015. p. 3.

15. General Directorate of Health Services, Department of Quality and Accreditation in Health. Standards of Accreditation in Health, Hospital Kit - v1.1/2015. Ankara: Pozitif Printing Press Ltd. Co., 2015: 3-15.

16. Greenfield D, Pawsey M, Braithwaite J. What Motivates Professionals to Engage in the Accreditation of Healthcare Organizations? Int J Qual Health Care 2011;23:8-14. [CrossRef]

17. Braithwaite J, Greenfield D, Westbrook J, Pawsey M, Westbrook M, Gibberd R, et al. Health Service Accreditation as a Predictor of Clinical and Organisational Performance: a Blinded, Random, Stratified Study. Qual Saf Health Care 2010;19:14-21.

18. Sax S, Marx M. Local Perceptions on Factors Influencing the Introduction of International Healthcare Accreditation in Pakistan. Health Policy Plan 2014;29:1021-30. [CrossRef]

19. Berktaş M, Beylik U, Kayral Hi, Avcı K, Cengiz C, Kavak DK, et al.
Denetim Yöntemi. In: Hastane Akreditasyon Denetim Rehberi. Ankara: Türkiye Sağlık Hizmetleri Kalite ve Akreditasyon Enstitüsü; 2017. p. 11-9.

20. Chen LW, Nguyen A, Jacobson JJ, Gupta N, Bekmuratova S, Palm D. Relationship Between Quality Improvement Implementation and Accreditation Seeking in Local Health Departments. Am J Public Health 2015;105:S295-302. [CrossRef]

21. Harrington, L., Pigman, H. Quality Measurement. In: Varkey P, (editor). Medical Quality Managenment Theory and Practice. USA: Jones and Barrlett Publishers, 2010: 29-40.

22. Shaw CD, Braithwaite J, Moldovan M, Nicklin W, Grgic I, Fortune T, et al.. Profiling Health-Care Accreditation Organizations: An International Survey. International Journal for Quality in Health Care 2013;25:222-31. [CrossRef]

23. Melo S. The Impact of Accreditation on Healthcare Quality Improvement: A Qualitative Case Study. J Health Organ Manag 2016;30:1242-58. [CrossRef]

24. van den Heuvel J, Niemeijer GC, Does RJ. Measuring Healthcare Quality: the Challenges . Int J Health Care Qual Assur 2013;26:269-78. [CrossRef] 